\title{
A comparison of serial position effects in implicit and explicit word-stem completion
}

\author{
BARBARA M. BROOKS \\ City University and Goldsmiths College, London, England
}

\begin{abstract}
In this study I examined a further possible dissociation between implicit and explicit memorywhether implicit memory produces serial position effects that are similar to those found in explicit memory. When implicit word-stem completion and explicit word-stem cued recall were compared, only the explicit test showed significant primacy and recency effects. The explicit test was sensitive to the order in which stimuli words were encoded, but the implicit test was not. This dissociation between implicit and explicit memory provides further evidence that conscious retrieval processes were not involved in the implicit test.
\end{abstract}

In their review of implicit memory, Roediger and McDermott (1993) stated that "Although examination of serial position effects has guided research about other issues in the study of memory, work on implicit memory is a clear exception at this point in time" (Roediger \& McDermott, 1993, p. 115). Referring specifically to primacy effects, they noted that "the voluminous implicit memory literature is almost mute on the issue as to whether a primacy effect exists on any implicit memory test"' (Roediger \& McDermott, 1993, p. 115).

The general consensus of opinion is that primacy effects arise from either more rehearsal (elaborative or rote) or greater attention devoted to the first few items in a tobe-remembered list than to the remaining items (Atkinson \& Shiffrin, 1968; Craik \& Lockhart, 1972; Glenberg et al., 1980; Rundus, 1971).

There is less consensus about the explanation for recency effects. The standard theory is that recency effects in free recall occur because subjects off-load the contents of their short-term memory prior to retrieving items from long-term memory (Craik, 1970; Glanzer \& Cunitz, 1966). Indeed, the recency effect disappears when a subject is asked to count backward for $30 \mathrm{sec}$ before recalling a list of words (Glanzer \& Cunitz, 1966). Doubts about this explanation arose when Bjork and Whitten (1974) reported a long-term recency effect, which occurred when $12 \mathrm{sec}$ of distractor task preceded the presentation of each study item. This long-term recency effect survived a 20 -sec retention interval in which the same distractor task was performed. Presumably, any items in short-term memory would have been displaced during this period. A number of explanations for the long-term recency effect have been proposed. They include the stra-

I am grateful to John Gardiner for his valuable advice before I started this study and in the preparation of this manuscript. I also thank Ruth Campbell, Felicia Gershberg, Ros Java, Henry Roediger, Dan Schacter, Ross Tasker, and an anonymous reviewer for helpful comments. Address correspondence to B. Brooks, Psychology Department, Goldsmiths College, University of London, New Cross, London SE14 6NW, England. tegic use of short-term memory (Poltrock \& MacLeod, 1977), the distinctiveness of the most recent items in a well-ordered series (Bjork \& Whitten, 1974; Glenberg et al., 1980), and retrieval using ordinal information (Baddeley \& Hitch, 1977; for a brief review see Greene, 1986).

Although they differ in their explanations, one assumption that all these theories make is that serial position effects reflect conscious retrieval of studied items. If this assumption is correct, serial position effects should not occur in implicit memory tests that assess indirect memory for a study episode. Implicit memory tests do not require subjects to consciously refer back to that episode and should not reflect any evidence of effortful retrieval. For example, a variable such as levels of processing, which manipulates the extent of conscious recollection in normal subjects, produces a significant effect in explicit but not in implicit memory tests (see Roediger \& McDermott, 1993, for a review).

There have been only four studies investigating whether primacy or recency effects occur in implicit memory tasks. The first, by Sloman, Hayman, Ohta, Law, and Tulving (1988, Experiment 1), indicated the existence of a recency effect and a single-item primacy effect in primed word-fragment completion. However, a closer examination of the experimental procedure in that study reveals that word-fragment completion involved both effortful and automatic memory processes. The instructions to the subjects stated that they were to "try to complete each fragment with a study-list word" (Sloman et al., 1988, p. 227). It is possible that the effortful component of the task was responsible for the serial position effects obtained.

In the second study, McKenzie and Humphreys (1991) found a significant recency effect in implicit word-stem completion. Their subjects completed significantly more word stems in an immediate test than they did in a delayed test. However, this recency effect is different from the short-lived recency component of the serial position curve, which disappears if a subject is asked to count backward 
for $30 \mathrm{sec}$ before recalling a list of words (Glanzer \& Cunitz, 1966).

In a more relevant previous study, Rybash and Osborne (1991) investigated serial position effects in free recall, implicit word-stem completion, and explicit word-stem cued recall. Their results indicated that all three tests produced a significant recency effect, but only free recall produced a significant primacy effect. Since no details about presentation orders were included in the methodology, it may be inferred that all of their subjects were presented with the study words in the same order. The first few words may have been less memorable or less easily completed than the remaining words, negating any possible primacy effects in all but the free-recall test. Similarly, the last few words may have been more memorable or more easily completed, producing a spurious recency effect in the cued-recall and word-stem completion tests. The significant recency effect in the word-stem completion and cued-recall tests was surprising because the test sheet contained 48 word stems, and any recency effects would presumably have disappeared before the relevant word stems were completed.

The latest study to investigate serial position effects in implicit word-stem completion was performed by Gershberg and Shimamura (in press). In two of three experiments they found transient primacy effects in implicit word-stem completion, which only occurred when the first half of the word stems tested were analyzed separately. They also found transient recency effects in one of three experiments. It should be noted, however, that they did not find consistent primacy effects in an explicit test of word-stem cued recall, nor did they find consistent recency effects in an immediate word-stem cued-recall test or even in an immediate free-recall test. There is therefore clearly a need for evidence of serial position effects in explicit tasks in conjunction with effects-or a lack of them-in implicit tasks.

The purpose of the present study was to provide reliable evidence as to whether serial position effects exist in implicit word-stem completion. An explicit test of word-stem cued recall was included, in which the test stimuli and study instructions were identical to the implicit test and only the test instructions differed. The results of these two tests therefore fulfilled the retrieval intentionality criterion of Schacter, Bowers, and Booker (1989) and could be directly compared. Any differences in the results would be attributable to the different test instructions.

\section{EXPERIMENT 1}

Experiment 1 was devised to investigate whether a primacy effect exists in an implicit word-stem completion test. Word stems were completed under explicit or implicit test instructions, but all other aspects of the study were the same. The order of presentation of words was rotated so that any significant results would be reliable and not contaminated by differences in word memorability or ease of completion. The serial positions of target word stems completed in the two tests were compared to see whether there were any differences in the effects obtained.

\section{Method}

Subjects. Thirty-six students from City University, London, and Goldsmiths College, University of London, age range 18-36 years, participated in the experiment. They were randomly allocated to two groups of 18 subjects each, and were tested either individually or in pairs.

Design and Materials. The design factors were test (implicit vs. explicit) and serial position; test was conducted between subjects, and serial position was conducted within subjects.

The stimulus material comprised 36 cards. Printed on each card in capital letters was a six-letter noun; these words were selected from materials prepared by Java (1991; Java \& Gardiner, 1991). The first three letters of each word formed the initial word stem of at least six words found in the Concise Oxford Dictionary.

The 36 cards were randomly allocated to two sets of 18 words. During the course of the experiment, the two card sets were counterbalanced so that when one set was presented as target words, the other set formed the lure words. The cards within each set were sequentially numbered from 1-18. The sequential order of each set of cards was kept constant during the course of the experiment, but the positional order varied. Each set of cards was advanced by two numbers after it had been presented once in the implicit and once in the explicit memory task. This procedure resulted in each word's appearing once in every other serial position.

The test order was held constant in the form of one test sheet of 40 three-letter word stems, printed in capital letters in two columns. The first 4 word stems were filler items, followed by word stems from both sets of words, listed in a pseudorandom order with no more than 3 consecutive word stems from one set.

Procedure. The subjects were randomly assigned to either the implicit or explicit test group and were tested either individually or in pairs. Both groups received the same preliminary instructions--to try to memorize the words they were about to see. One set of 18 words was then shown to them on cards, one card at a time for $2 \mathrm{sec}$. After 1 subject from each group had been presented with the cards in an identical order, the positional order of the cards was advanced by 2 words (while keeping the sequential order the same) before the cards were presented again. In addition, alternate subjects in each group received a different set of cards.

The subjects were tested immediately. In the explicit test, they were instructed to write completions to the word stems of any words they could remember from the study cards. They were informed of the presence of some lure word stems and were instructed to leave these blank. They were also asked not to guess completions. In the implicit test, the subjects were asked to complete every word stem with the first word that came to mind. If a word did not immediately come to mind, they were to leave it blank. They were advised that word stems from some study words would be included in the list, but that they should only complete word stems with these words if they were the first words that came to mind. Three minutes were allowed for this task.

On completion, the subjects in the implicit test were asked whether they had actually completed word stems with the first word that came to mind, or whether they had deliberately tried to remember words from the study episode. All the subjects reported that they had completed the word stems with the first word that had come to mind.

\section{Results and Discussion}

There was a significant priming effect in the implicit memory test (target word-stem completion, $p=.552$; lure word-stem completion, $p=.197)[t(17)=9.94]$. Since 
the level of completion of lure word stems was relatively low, baseline completion should not have affected any possible serial position effects. Similarly, incorrect completions in the explicit test were very low (target word-stem completion, $p=.586$; wrong completion, $p=.03$ ) $[t(17)=13.42]$, indicating that guessing should not have affected serial position effects in the explicit test.

The results of Experiment 1 are shown in Table 1. A graph of these results, collapsed across three consecutive serial positions to reduce noise and with baseline completion subtracted in the implicit test, is shown in Figure 1. It appears from the graph that explicit word-stem cued recall produced a primacy effect, but implicit wordstem completion did not.

To investigate this interpretation of the data, a $2 \times 2$ analysis of variance (ANOVA) was performed with one between-subjects factor (test; implicit vs. explicit) and one within-subjects factor (serial position; probability of recall from primacy Serial Positions 1-3 vs. probability of recall from asymptote Serial Positions 7-12). (The choice of these serial positions as indicators of primacy effects and asymptote levels was arbitrary and did not influence the results.) The ANOVA was performed on the data for studied items, without subtracting baselines (i.e., not the data shown in Figure 1).

The alpha level was set at .05 in all the statistical analyses. The main effect of test was not significant $[F(1,34)=$ $1.78, M S_{\mathrm{e}}=0.86$, but that of serial position was $\left[F(1,34)=8.59, M S_{\mathrm{e}}=0.39\right]$, and there was a significant interaction between test and serial position $[F(1,34)=$ 4.73, $M S_{\mathrm{e}}=0.39$ ]. Separate ANOVAs were performed between the primacy and asymptote serial positions from each test to find the reason for this interaction. In the implicit test, the difference between these serial positions was not significant $\left[F(17)=0.29, M S_{\mathrm{e}}=0.39\right]$, but it was significant in the explicit test $\left[F(17)=13.11, M S_{\mathrm{e}}=\right.$ 0.39].

Table 1

Percentage of Target Words Completed as a Function of Serial Position and Test in Experiments 1 and 2

\begin{tabular}{cccccc}
\hline \multirow{2}{*}{$\begin{array}{c}\text { Serial } \\
\text { Position }\end{array}$} & \multicolumn{2}{c}{ Experiment 1} & & \multicolumn{2}{c}{ Experiment 2 } \\
\cline { 2 - 3 } \cline { 5 - 6 } & Implicit & Explicit & & Implicit & Explicit \\
\hline 1 & 67 & 94 & 67 & 86 \\
2 & 44 & 78 & & 58 & 72 \\
3 & 61 & 61 & 58 & 61 \\
4 & 56 & 50 & 64 & 58 \\
5 & 67 & 61 & 53 & 67 \\
6 & 50 & 61 & 75 & 50 \\
7 & 44 & 44 & 69 & 58 \\
8 & 56 & 50 & 64 & 50 \\
9 & 56 & 56 & 64 & 56 \\
10 & 44 & 56 & 75 & 67 \\
11 & 56 & 61 & 67 & 61 \\
12 & 67 & 50 & 69 & 64 \\
13 & 44 & 56 & 61 & 56 \\
14 & 61 & 56 & 67 & 61 \\
15 & 50 & 56 & 67 & 72 \\
16 & 50 & 56 & 67 & 72 \\
17 & 61 & 50 & 64 & 69 \\
18 & 61 & 61 & 69 & 81 \\
\hline
\end{tabular}

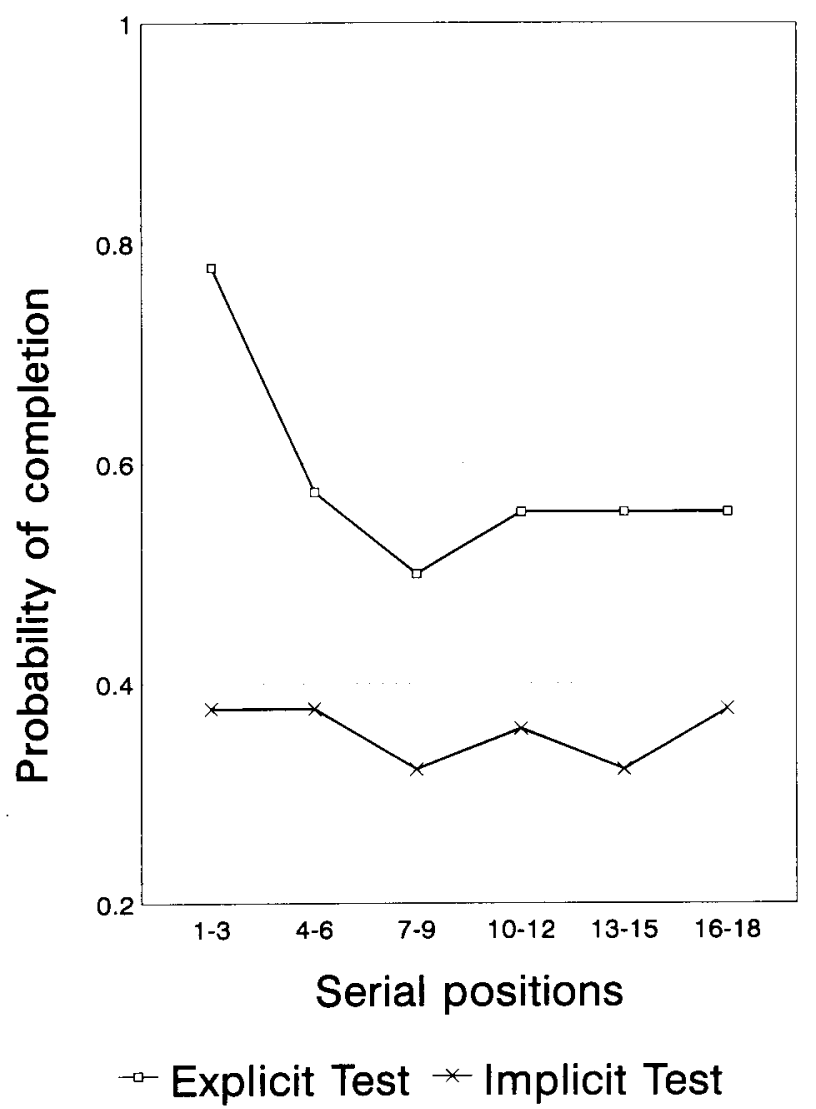

Figure 1. Experiment 1: Probability of completion of target words as a function of serial position and test.

These results show a primacy effect in explicit cued recall, but not in implicit word-stem completion. This difference could not be attributed to greater variability in the implicit test, since both tests had identical mean square error terms.

The design of the test sheet in Experiment 1 made it unlikely that a recency effect would occur in either testany possible recency effects would have disappeared during the time it took the subjects to work through the four filler word stems and intervening word stems. It was therefore necessary to alter the test sheet so that the most recently seen words were presented first in order to capture any possible recency effects.

\section{EXPERIMENT 2}

Because serial position recency effects are short lived when words are encoded without an interpolating task (Craik, 1970; Glanzer \& Cunitz, 1966), it was necessary to design a new test sheet that would provide an optimal test for recency. On this new test sheet, word stems of the words on the study cards appeared in the reverse order, beginning with the word stem of the last word presented at study. 


\section{Method}

Subjects. Seventy-two students and staff members from City University, London, and Goldsmiths College, University of London, age range $18-42$ years, participated in the experiment. They were randomly allocated to two groups of 36 subjects each, and were tested individually.

Design and Materials. The experimental design was similar to that of Experiment 1, except the cards were only advanced by one word after they had been presented to 1 subject from each experimental group. This procedure allowed full counterbalancing of serial positions, since every word appeared once in every serial position for each test.

The stimuli were also identical to those of Experiment 1, but the test sheet was designed to capture any possible recency effects. It contained 36 three-letter word stems, printed in capital letters and equally spaced around the circumference of a circle; word stems from each set appeared alternately. The test sheet was covered by a cardboard circular mask, fixed at the center, with a three-sided cutout on the circumference that allowed one word stem to be viewed at a time. When the mask was rotated in a clockwise direction, the subjects saw word stems from the study cards, in reverse order, interspersed by lure word stems.

Procedure. The procedure was also similar to that of Experiment 1, with the following differences. In Experiment 2, the subjects were all tested individually. The positional order of the cards was advanced by one word instead of two after presentation in the implicit and explicit tests. This resulted in each word's appearing once in every serial position. Immediately after seeing the study words, the subjects were given a test sheet with the mask open at the lure word preceding the last study word they had seen. Additional instructions to move the mask clockwise for each word stem were given. The subjects were only allowed to view each word stem once.

\section{Results and Discussion}

In the implicit test, baseline word-stem completion was again relatively low $(p=.205)$ compared with target word-stem completion $(p=.654)[t(35)=14.16]$. Similarly, wrong completions in the explicit test were low $(p=.073)$ compared with target completions $(p=.645)$ $[t(35)=18.44]$.

The results of Experiment 2 are shown in Table 1. A graph of these results, collapsed across three consecutive serial positions to reduce noise and with baseline completion subtracted in the implicit test, is shown in Figure 2. It appears from the graph that explicit word-stem cued recall produced a primacy and recency effect, but implicit word-stem completion did not.

A $2 \times 3$ ANOVA was performed on studied items with one between-subjects factor (test; implicit vs. explicit) and one within-subjects factor (serial position; probability of recall from primacy Serial Positions 1-3 vs. asymptote Serial Positions 7-12 vs. recency Serial Positions 16-18) to calculate whether there were significant serial position effects in the explicit test compared with the implicit test. (The choice of these serial positions as indicators of primacy, asymptote, and recency was arbitrary and did not influence the results.) Neither the main effect of test $\left[F(1,70)=0.63, M S_{\mathrm{e}}=0.97\right]$ nor the main effect of serial position $\left[F(2,140)=1.44, M S_{\mathrm{e}}=0.51\right]$ was significant, but there was a significant interaction between test and serial position $\left[F(2,140)=3.81, M S_{\mathrm{e}}=0.51\right]$.

One-way ANOVAs were performed on each test to investigate the reason for this interaction. In the implicit test, the main effect of serial position was not significant $\left[F(2,70)=0.97, M S_{\mathrm{e}}=0.45\right]$, but it was significant in the explicit test $\left[F(2,70)=3.95, M S_{\mathrm{e}}=0.57\right]$. In the

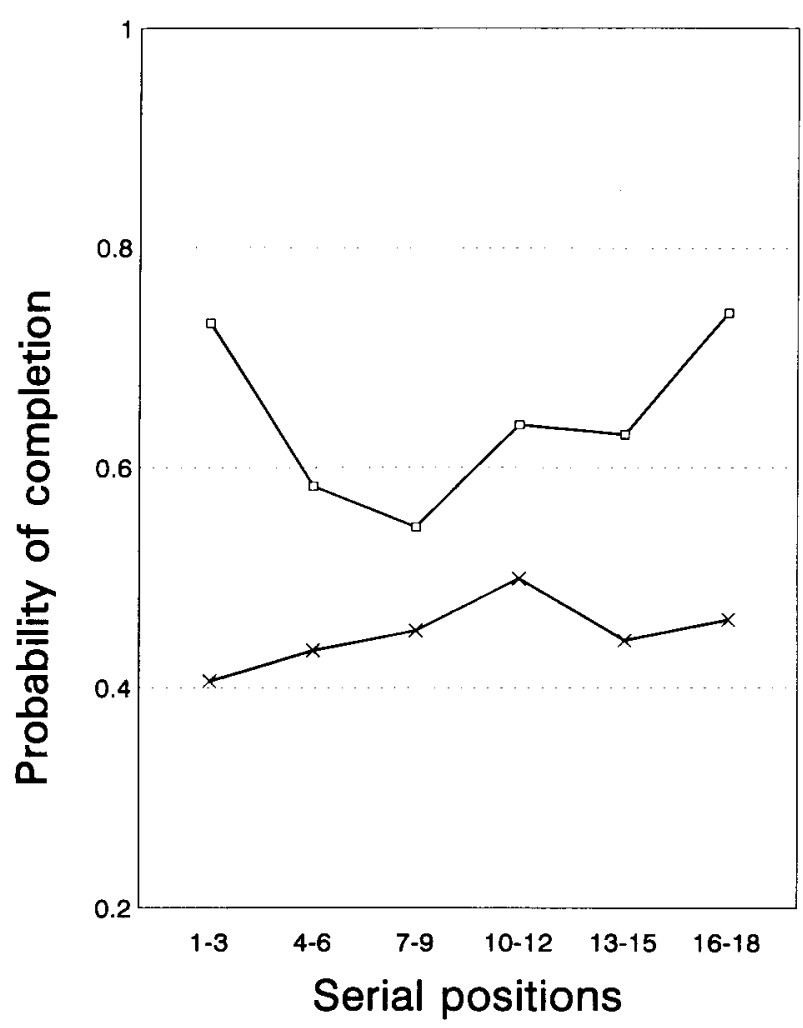

$\rightarrow$ Explicit Test $*$ Implicit Test

Figure 2. Experiment 2: Probability of completion of target words as a function of serial position and test.

explicit test, a paired $t$ test between the primacy and asymptote probabilities was significant $[t(35)=2.51]$, as was a paired $t$ test between the asymptote and recency probabilities $[t(17)=2.60]$.

These results show that primacy and recency effects were found in explicit word-stem cued recall but not in implicit word-stem completion. This difference could not be attributed to greater variability in the implicit test, since this test had a lower mean square error term than the explicit test.

When the results of the two experiments are compared, it is apparent that target word-stem completion rates in the implicit tests differed (Experiment $1, p=.552$; Experiment $2, p=.654$ ). Since the stimuli and study conditions were identical, it is probable that this difference was due to the different test sheets. The absence of four filler word stems in Experiment 2 may be one contributory factor, but a further factor might be that in Experiment 2 word stems were presented one at a time, which was more similar to the manner in which they were encoded. The increased similarity between encoding and test conditions may have provided more optimal conditions for retrieval from implicit memory.

A comparison of the graphs of the two explicit tests shows that the primacy effect was higher in Experiment 1 
than in Experiment 2. This difference may be because word stems of studied words appeared in the reverse order on the test sheet in Experiment 2. The first words encoded (from which the primacy effect is measured) were therefore the last word stems completed, resulting in a lower primacy effect.

\section{GENERAL DISCUSSION}

There was little indication of serial position effects in the implicit test in either experiment, whereas the explicit test, which was identical to the implicit test in all but the test instructions, showed a primacy effect in Experiments 1 and 2 and a recency effect in Experiment 2.

The lack of serial position effects in the implicit tests differed from the findings of Sloman et al. (1988, Experiment 1), discussed in the introduction. The most probable reason for this difference was the intentional use of conscious retrieval in Sloman et al.'s study.

The results of the present study also differed from those of Rybash and Osborne (1991) and Gershberg and Shimamura (in press), also discussed previously. The main difference between the three studies was the different methodological procedures used. For example, the order in which the target words were presented to the subjects differed be tween the studies. In Rybash and Osborne's study, all the subjects studied the same list of target words in the same order. In Gershberg and Shimamura's study, each subject studied one of two target-word lists in one of two different orders. In this study, the subjects also studied one of two target-word lists, but each list was presented in 9 different orders in Experiment 1 and in 18 different orders in Experiment 2. Only by such an extensive rotation of words at encoding can differences in word frequency and ease of completion of word stems be adequately controlled.

As well as providing evidence for the lack of serial position effects in implicit memory, these results provide tangible evidence that the testaware subjects performed according to instructions in the implicit test If they had been using explicit strategies, it is probable that serial position effects in the implicit test would have been similar to those in the explicit test.

In conclusion, the finding that implicit word-stem completion does not show serial position effects but that explicit word-stem cued recall does, reveals another dissociation between tests of implicit and explicit memory and provides further evidence that conscious retrieval processes are not involved in this implicit memory test.

\section{REFERENCES}

AtKinson, R. C., \& Shiffrin, R. M. (1968). Human memory: A proposed system and its control processes. In $K$. W. Spence \& J. T. Spence (Eds.), The psychology of learning and motivation (Vol. 2, pp. 89-195). London: Academic Press.
Baddeley, A. D., \& Hitch, G. J. (1977). Recency re-examined. In S. Dornic (Ed.), Attention and performance VI (pp. 647-667). Hillsdale, NJ: Erlbaum.

BJoRk, R. A., \& Whitten, W. B. (1974). Recency-sensitive retrieval processes in long-term free recall. Cognitive Psychology, 6, 173-189.

CRAIK, F. I. M. (1970). The fate of primary items in free recall. Journal of Verbal Learning \& Verbal Behavior, 9, 143-148.

Craik, F. I. M., \& LockHART, R. S. (1972). Levels of processing: A framework for memory research. Journal of Verbal Learning \& Verbal Behavior, 11, 671-684.

Gershberg, F. B., \& Shimamura, A. P. (in press). Serial position effects in implicit and explicit tests of memory. Journal of Experimental Psychology: Learning, Memory, \& Cognition.

Glanzer, M., \& Cunitz, A. R. (1966). Two storage mechanisms in free recall. Journal of Verbal Learning \& Verbal Behavior, 13, 114-131.

Glenberg, A. M., Bradley, M. M., Stevenson, J. A., Kraus, T. A., Tkachuk, M. J., GretZ, A. L., Fish, J. H., \& Turpin, B. M. (1980). A two-process account of long-term serial position effects. Journal of Experimental Psychology: Human Learning \& Memory, 6, 355-369.

GreENe, R. L. (1986). Sources of recency effects in free recall. Psychological Bulletin, 99, 221-228.

JAVA, R. I. (1991). Memory, age, and conscious awareness. Unpublished doctoral dissertation, City University, London.

JAVA, R. I., \& Gardiner, J. M. (1991). Priming and aging: Further evidence of preserved memory function. American Joumal of Psychology, 104, 89-100.

McKenZie, W. A., \& HumphreYs, M. S. (1991). Recency effects in direct and indirect memory tasks. Memory \& Cognition, 19, 321-331.

Poltrock, S. E., \& MacLeod, C. M. (1977). Primacy and recency in the continuous distractor paradigm. Journal of Experimental Psychology: Human Learning \& Memory, 3, 560-571.

Roediger, H. L., III, \& MCDermotT, K. B. (1993). Implicit memory in normal human subjects. In H. Spinnler \& F. Boller (Eds.), Handbook of neuropsychology (Vol. 8, pp. 63-131). Amsterdam: Elsevier.

RuNDus, D. (1971). Analysis of rehearsal processes in free recall. Journal of Experimental Psychology, 89, 63-77.

Rybash, J. M., \& OsBorNe, J. L. (1991). Implicit memory, the serial position effect, and test awareness. Bulletin of the Psychonomic Society, 29, 327-330.

SCHACTER, D. L., BOWERS, J., \& BOOKER, J. (1989). Intention, awareness and implicit memory: The retrieval intentionality criterion. In S. Lewandowsky, J. C. Dunn, \& K. Kirsner (Eds.), Implicit memory: Theoretical issues (pp. 47-65). Hillsdale, NJ: Erlbaum.

Sloman, S. A., Hayman, C. A. G., Ohta, N., Law, J., \& TulVING, E. (1988). Forgetting in primed fragment completion. Journal of Experimental Psychology: Learning, Memory, \& Cognition, 14, 223-239.

(Manuscript received December 3, 1993; revision accepted for publication March 1, 1994.) 